\title{
Isolation and Quantification of Ginsenoside Rh23, a New Anti-Melanogenic Compound from the Leaves of Panax ginseng
}

\author{
Dae Young Lee ${ }^{1}\left(\mathbb{D}^{(}\right)$, Hyoung-Geun $\mathrm{Kim}^{2}$, Yeong-Geun Lee ${ }^{2}$, Jin Hee Kim ${ }^{3}$, Jae Won Lee ${ }^{1}$ (1), \\ Bo-Ram Choi ${ }^{1}$, In-Bae Jang ${ }^{1}$, Geum-Soog Kim ${ }^{1}$ and Nam-In Baek ${ }^{2, *}$ \\ 1 Department of Herbal Crop Research, National Institute of Horticultural and Herbal Science, RDA, \\ Eumseong 27709, Korea; dylee0809@gmail.com (D.Y.L.); jaewon3@gmail.com (J.W.L.); \\ bmcbr@korea.kr (B.-R.C.); ikanet@korea.kr (I.-B.J.); kimgs0725@korea.kr (G.-S.K.) \\ 2 Department of Oriental Medicine Biotechnology, Kyung Hee University, Yongin 17104, Korea; \\ zwang05@naver.com (H.-G.K.); lyg629@nate.com (Y.-G.L.) \\ 3 College of Herbal Bio-industry, Daegu Haany University, Gyeongsan 38610, Korea; gonogo1@nate.com \\ * Correspondence: nibaek@khu.ac.kr; Tel.: +82-31-201-2661; Fax: +82-31-204-8116
}

Received: 28 November 2017; Accepted: 26 January 2018; Published: 29 January 2018

\begin{abstract}
A new ginsenoside, named ginsenoside Rh23 (1), and 20-O- $\beta$-D-glucopyranosyl- $3 \beta, 6 \alpha$, $12 \beta, 20 \beta, 25$-pentahydroxydammar-23-ene (2) were isolated from the leaves of hydroponic Panax ginseng. Compounds were isolated by various column chromatography and their structures were determined based on spectroscopic methods, including high resolution quadrupole/time of flight mass spectrometry (HR-QTOF/MS), nuclear magnetic resonance (NMR) spectroscopy, and infrared (IR) spectroscopy. To determine anti-melanogenic activity, the change in the melanin content in melan-a cells treated with identified compounds was tested. Additionally, we investigated the melanin inhibitory effects of ginsenoside $\mathrm{Rh} 23$ on pigmentation in a zebrafish in vivo model. Compound 1 inhibited potent melanogenesis in melan-a cells with $37.0 \%$ melanogenesis inhibition at $80 \mu \mathrm{M}$ and also presented inhibition on the body pigmentation in zebrafish model. Although compound 2 showed slightly lower inhibitory activity than compound $\mathbf{1}$, it also showed significantly decreased melanogenesis in melan-a cell and in zebrafish model. These results indicated that compounds isolated from hydroponic $P$. ginseng may be used as new skin whitening compound through the in vitro and in vivo systems. Furthermore, this study demonstrated the utility of MS-based compound 1 for the quantitative analysis. Ginsenoside Rh23 (1) was found at a level of $0.31 \mathrm{mg} / \mathrm{g}$ in leaves of hydroponic P. ginseng.
\end{abstract}

Keywords: ginsenoside Rh23; Panax ginseng; NMR; UPLC-QTOF/MS; zebrafish; quantitative analysis

\section{Introduction}

Panax ginseng C.A. Meyer is a very famous traditional medicinal herb in Asian countries. Panax originates from a "panacea", which means cure-all for diseases. P. ginseng is a perennial herbaceous plant belonging to the Araliaceae family [1]. Four- to six-year-old roots of $P$. ginseng are mainly used for therapeutic purposes. Flowers bloom in June, and the leaves, having a palmate shape, of. P. ginseng have been mainly cultivated in East Asia, including Korea, China, and Japan [2]. To date, many studies have been reported about the chemical constituents of ginseng roots, leaves, and berries; more than 100 kinds of ginsenosides have been isolated. Various bioactivities of $P$. ginseng were reported, such as the enhancement of immunomodulatory activity, nutritional fortification, improvements of liver function, anti-diabetes, anti-cancer, anti-apoptotic, and anti-oxidant activities [3-10]. 
Currently, the interest in well-being-related agricultural products of high quality is gradually increasing, leading to hydroponic cultivation of ginseng. Hydroponic cultivation has the advantages of simple cultivation process and shorter growth period than soil cultivation. Hydroponic ginseng needs only 2-4 months in a system that controls temperature, pesticide-free, moisture, light, organic ingredients, etc. [11]. The leaves of soil cultivation ginseng are not used for medicinal purpose and functional vegetables, while the leaves of hydroponic ginseng can be used. In previous study, the contents and composition of ginsenosides in different parts, such as leaves, roots, and fruits of ginseng, were investigated after short-term hydroponic system [12]. The total ginsenoside content of the ginseng leaves was found to be significantly higher at $15.30 \%$, while the content of the ginseng roots at $1.27 \%$. Additionally, the contents of the major ginsenosides components produced in the ginseng leaves cultured in the hydroponic system were observed in the order of: $\operatorname{Rg} 1>\operatorname{Rd}>\operatorname{Re}>\operatorname{Rc}>\operatorname{Rb} 2>\operatorname{Rg} 2>$ $\mathrm{Rb} 1>\mathrm{Rh} 1>\mathrm{Rf}$ [11]. Conclusively, hydroponic conditions led to high ginsenoside content, and the total ginsenoside content in leaves was significantly higher than in roots, suggesting ginseng leaves might be a good source as functional vegetables and medicinal herbs.

Several the known whitening compounds, such as arbutin and kojic acid, have been investigated for their effectiveness in reducing melanogenesis [13]. Unfortunately, it is clearly necessary to find safer and more effective skin-whitening agents, due to the carcinogenic potential of kojic acid and both the safety and side-effects of arbutin [14]. Thereby, a great deal of attention has continuously investigated on the development of new natural products in the cosmetics industry $[15,16]$. Several studies have reported the inhibition of melanin synthesis from P. ginseng grown in soil [17-20]. However, these studies were reported with well-known compounds, such as cinnamic acid and phenolic compounds, and whitening activity has not been reported from the leaves of hydroponic P. ginseng (HPGL). Our ongoing work led to the isolation of minor ginsenosides from HPGL. Usually, ginsenosides in minor or trace amounts cannot be detected with HPLC. Otherwise, the analytical time is very long, which is not convenient for qualifying the ginsenosides in ginseng spices [21,22]. To rapidly quantify novel compounds, a rapid and sensitive method, which can thoroughly detect the trace amounts of novel compounds, should be established. In the present study, a sensitive ultrahigh performance liquid chromatography coupled with quadrupole/time of flight mass spectrometry (UPLC-QTOF-MS) method was established to quantify of new compound.

Based on the above description, in this work, isolation and identification of a new compound, including physical properties and quantification, were revealed by spectroscopic methods, and their anti-melanogenic activities were investigated through in vitro and in vivo systems.

\section{Results and Discussion}

Leaves of hydroponic Panax ginseng (HPGL) were extracted with aqueous $\mathrm{MeOH}$ and partitioned into ethyl acetate (EtOAc), $n$-butanol $(n-\mathrm{BuOH})$, and $\mathrm{H}_{2} \mathrm{O}$ fractions, respectively. Repeated $\mathrm{SiO}_{2}$ and ODS column chromatographies of the $n$ - $\mathrm{BuOH}$ fraction afforded one new ginsenoside (1), and one rare ginsenoside (2) was isolated from the EtOAc fraction of HPGL.

Compound 1, white powder (methanol), showed a purple color on the TLC, by spraying $10 \%$ $\mathrm{H}_{2} \mathrm{SO}_{4}$ and heating. The molecular formula was determined to be $\mathrm{C}_{37} \mathrm{H}_{64} \mathrm{O}_{10}$ from the quasi-molecular ion peak $m / z 713.44723[\mathrm{M}+\mathrm{COOH}]^{-}$in the negative QTOF/MS. IR spectrum suggested the presence of hydroxyl group $\left(3377 \mathrm{~cm}^{-1}\right)$ and the double bond $\left(1647 \mathrm{~cm}^{-1}\right)$. The ${ }^{1} \mathrm{H}-\mathrm{NMR}$ spectrum (Table 1 and Supplementary Materials) showed two olefin methine proton signals $\left(\delta_{\mathrm{H}} 6.02,5.64\right)$, three oxygenated methine proton signals $\left(\delta_{\mathrm{H}} 4.38,4.03,3.49\right)$, one methoxy proton signal $\left(\delta_{\mathrm{H}} 3.18\right)$, and eight singlet methyl proton signals $\left(\delta_{\mathrm{H}} 1.94,1.55,1.43,1.33,1.31,1.14,1.04,0.92\right)$, indicating compound 1 has a tetracyclic triterpene moiety including one double bond with trans conformation, and three hydroxyl groups. Additionally, compound $\mathbf{1}$ is confirmed to be a protopanaxatriol (PPT)-type from the chemical shift of a methyl proton signal at $\delta_{\mathrm{H}} 1.94(\mathrm{H}-28)$. The chemical shift of $\mathrm{H}-28$ in protopanaxadiol (PPD)-type is usually observed at ca $\delta_{\mathrm{H}} 1.30$ [23]. Furthermore, a hemiacetal proton signal $\left(\delta_{\mathrm{H}} 5.15\right)$, and several oxygenated methine and methylene proton signals at $\delta_{\mathrm{H}} 4.45-3.95$ were observed as the 
signals of a sugar moiety. From the coupling constant of the anomer proton signal $(J=7.6 \mathrm{~Hz})$, both the hemiacetal proton and H-2 of the sugar moiety were in an axial arrangement. The combination of the above-mentioned data concluded compound 1 to be a protopanaxatriol monoglycoside. The ${ }^{13} \mathrm{C}-\mathrm{NMR}$ spectrum exhibited 37 carbon signals due to triterpene, methoxy, and hexose moieties. Two olefin methine carbons $\left(\delta_{C} 138.5(\mathrm{C}-24), 126.8(\mathrm{C}-23)\right)$, one oxygenated quaternary carbon $\left(\delta_{C} 74.9(\mathrm{C}-25)\right)$, three oxygenated methine carbons $\left(\delta_{C} 78.5(\mathrm{C}-3), 70.3(\mathrm{C}-12), 67.7(\mathrm{C}-6)\right)$, one methoxy carbon $\left(\delta_{C}\right.$ $\left.50.2\left(25-\mathrm{OCH}_{3}\right)\right)$, and eight methyl carbons ( $\delta_{\mathrm{C}} 31.9(\mathrm{C}-28), 26.3(\mathrm{C}-27), 26.1(\mathrm{C}-26), 23.0(\mathrm{C}-21), 17.6$ (C-18), 17.4 (C-19), 17.3 (C-30), 16.4 (C-29)) signals were observed for the aglycon moiety. The NMR data of compound 1 were similar to those of compound 2, with the exception of the chemical shift for an oxygenated quaternary carbon, i.e., C-25. Additionally, the sugar was identified as a $\beta$-glucopyranose from the carbon signals hemiacetal $\left(\delta_{\mathrm{C}} 98.3,\left(\mathrm{C}-1^{\prime}\right)\right)$, four oxygenated methines $\left(\delta_{C} 78.9\left(\mathrm{C}-3^{\prime}\right), 78.2\left(\mathrm{C}-5^{\prime}\right), 75.2\left(\mathrm{C}-2^{\prime}\right), 71.6\left(\mathrm{C}-4^{\prime}\right)\right)$, and one oxygenated methylene $\left(\delta_{C} 63.0\left(\mathrm{C}-6^{\prime}\right)\right)$. In the gradient heteronuclear multiple bond correlation (gHMBC) spectrum, a long-range correlation was observed between the anomeric proton signal $\left(\delta_{\mathrm{H}} 5.15\left(\mathrm{H}-1^{\prime}\right)\right)$ and the oxygenated quaternary carbon signal of the aglycon $\left(\delta_{C} 83.0(\mathrm{C}-20)\right)$, indicating that the $\beta$-glucopyranose were linked to the hydroxyl of C-20 (Figure 1). In addition, the correlation between the methoxy proton signal $\left(\delta_{\mathrm{H}} 3.18\right.$ $\left.\left(25-\mathrm{OCH}_{3}\right)\right)$ and the oxygenated quaternary carbon signal $\left(\delta_{\mathrm{c}} 74.9(\mathrm{C}-25)\right)$ indicated that the methoxy was linked to $\mathrm{C}-25$ (Figure 1). Based on the above data, the chemical structure of 1 was determined to be 20-O- $\beta$-D-glucopyranosyl-3 $\beta, 6 \alpha, 12 \beta, 20 \beta$-tetrahydroxy-25-methoxydammar-23-ene, and named as ginsenoside Rh23. Compound 2 was identified to be $20-O-\beta$-D-glucopyranosyl-3 $\beta, 6 \alpha, 12 \beta, 20 \beta, 25$ pentahydroxydammar-23-ene from the comparisons of NMR and MS data with those reported in the literature [23,24] (Figure 1). Compounds 1 and 2 were, for the first time, isolated from HPGL.

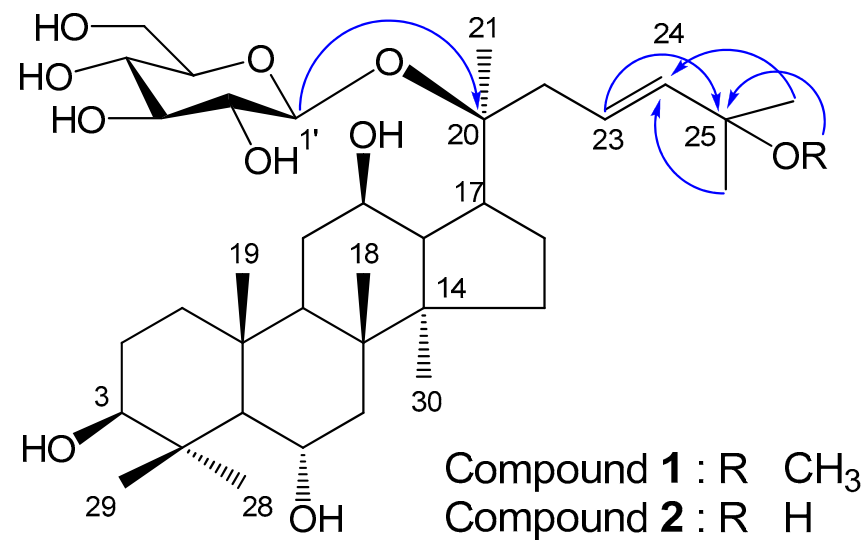

Figure 1. Chemical structures of compounds $\mathbf{1}$ and $\mathbf{2}$, and key gHMBC (arrow) correlations of $\mathbf{1}$.

Table 1. ${ }^{1} \mathrm{H}-(400 \mathrm{MHz})$ and ${ }^{13} \mathrm{C}-\mathrm{NMR}(100 \mathrm{MHz})$ spectra of compounds 1 and 2 (in pyridine- $d_{5}$ ).

\begin{tabular}{ccccc}
\hline \multicolumn{2}{c}{ Compound $\mathbf{1}$} & \multicolumn{2}{c}{ Compound 2 } \\
\hline No. & $\boldsymbol{\delta}_{\mathbf{H}}$ in $\mathbf{p p m}, \boldsymbol{J}$ in $\mathbf{~ H z}$ & $\boldsymbol{\delta}_{\mathbf{C}}$ & $\boldsymbol{\delta}_{\mathbf{H}}$ in $\mathbf{p p m}, \boldsymbol{J}$ in $\mathbf{~ H z}$ & $\boldsymbol{\delta}_{\mathbf{C}}$ \\
\hline 1 & $1.73,1.02$ & 39.4 & $1.70,1.00$ & 39.5 \\
2 & $1.84,1.83$ & 28.1 & $1.83,1.81$ & 28.1 \\
3 & $3.49(1 \mathrm{H}, \mathrm{dd}, J=11.6,4.8 \mathrm{~Hz})$ & 78.5 & $3.50(1 \mathrm{H}, \mathrm{dd}, J=11.2,5.2 \mathrm{~Hz})$ & 78.5 \\
4 & - & 40.3 & - & 40.3 \\
5 & $1.21(1 \mathrm{H}, \mathrm{d}, J=10.4 \mathrm{~Hz})$ & 61.8 & $1.20(1 \mathrm{H}, \mathrm{d}, J=10.4 \mathrm{~Hz})$ & 61.8 \\
6 & $4.38(1 \mathrm{H}, \mathrm{m})$ & 67.7 & $4.37(1 \mathrm{H}, \mathrm{m})$ & 67.7 \\
7 & $1.92,1.87$ & 47.4 & $1.91,1.86$ & 47.4 \\
8 & - & 41.2 & - & 49.8 \\
9 & 1.54 & 49.3 & 1.53 & 39.3 \\
10 & - & 39.4 & - & 31.0 \\
11 & $2.11,1.58$ & 31.0 & $2.08,1.53$ & 70.4 \\
\hline 12 & $4.03(1 \mathrm{H}, \mathrm{m})$ & 70.3 & $4.03(1 \mathrm{H}, \mathrm{m})$ & \\
\hline
\end{tabular}


Table 1. Cont.

\begin{tabular}{|c|c|c|c|c|}
\hline \multirow[b]{2}{*}{ No. } & \multicolumn{2}{|l|}{ Compound 1} & \multicolumn{2}{|l|}{ Compound 2} \\
\hline & $\delta_{\mathrm{H}}$ in ppm, $J$ in $\mathrm{Hz}$ & $\delta_{C}$ & $\delta_{H}$ in ppm, $J$ in $\mathrm{Hz}$ & $\delta_{C}$ \\
\hline 13 & $1.97(1 \mathrm{H}, \mathrm{m})$ & 49.3 & $1.97(1 \mathrm{H}, \mathrm{m})$ & 49.2 \\
\hline 14 & - & 51.4 & - & 51.4 \\
\hline 15 & $1.61,0.99$ & 30.7 & $1.57,0.99$ & 30.6 \\
\hline 16 & $1.74,1.40$ & 26.4 & $1.72,1.41$ & 26.4 \\
\hline 17 & $2.45(1 \mathrm{H}, \mathrm{m})$ & 52.1 & $2.40(1 \mathrm{H}, \mathrm{m})$ & 52.4 \\
\hline 18 & $1.14(3 \mathrm{H}, \mathrm{s})$ & 17.6 & $1.13(3 \mathrm{H}, \mathrm{s})$ & 17.6 \\
\hline 19 & $1.04(3 \mathrm{H}, \mathrm{s})$ & 17.4 & $1.03(3 \mathrm{H}, \mathrm{s})$ & 17.4 \\
\hline 20 & - & 83.0 & - & 83.2 \\
\hline 21 & $1.55(3 \mathrm{H}, \mathrm{s})$ & 23.0 & $1.55(3 \mathrm{H}, \mathrm{s})$ & 22.9 \\
\hline 22 & $\begin{array}{l}3.07(1 \mathrm{H}, \mathrm{dd}, J=14.0,5.6 \mathrm{~Hz}) \\
2.64(1 \mathrm{H}, \mathrm{dd}, J=14.0,8.8 \mathrm{~Hz})\end{array}$ & 39.6 & $\begin{array}{l}3.01(1 \mathrm{H}, \mathrm{dd}, J=14.0,6.0 \mathrm{~Hz}) \\
2.71,(1 \mathrm{H}, \mathrm{dd}, J=14.0,8.8 \mathrm{~Hz})\end{array}$ & 39.3 \\
\hline 23 & $6.02(1 \mathrm{H}, \mathrm{ddd}, J=15.6,8.8,5.6 \mathrm{~Hz})$ & 126.8 & $6.26(1 \mathrm{H}, \mathrm{ddd}, J=15.6,8.8,6.0 \mathrm{~Hz})$ & 122.8 \\
\hline 24 & $5.64(1 \mathrm{H}, \mathrm{d}, J=15.6 \mathrm{~Hz})$ & 138.5 & $5.96(1 \mathrm{H}, \mathrm{d}, J=15.6 \mathrm{~Hz})$ & 142.0 \\
\hline 25 & - & 74.9 & -1 & 69.0 \\
\hline 26 & $1.31(3 \mathrm{H}, \mathrm{s})$ & 26.1 & $1.51(3 \mathrm{H}, \mathrm{s})$ & 30.6 \\
\hline 27 & $1.33(3 \mathrm{H}, \mathrm{s})$ & 26.3 & $1.50(3 \mathrm{H}, \mathrm{s})$ & 30.8 \\
\hline 28 & $1.94(3 \mathrm{H}, \mathrm{s})$ & 31.9 & $1.95(3 \mathrm{H}, \mathrm{s})$ & 31.9 \\
\hline 29 & $1.43(3 \mathrm{H}, \mathrm{s})$ & 16.4 & $1.42(3 \mathrm{H}, \mathrm{s})$ & 16.4 \\
\hline 30 & $0.92(3 \mathrm{H}, \mathrm{s})$ & 17.3 & $0.89(3 \mathrm{H}, \mathrm{s})$ & 17.2 \\
\hline $\mathrm{OCH}_{3}$ & $3.18(3 \mathrm{H}, \mathrm{s})$ & 50.2 & - & - \\
\hline $1^{\prime}$ & $5.15(1 \mathrm{H}, \mathrm{d}, J=7.6 \mathrm{~Hz})$ & 98.3 & $5.15(1 \mathrm{H}, \mathrm{d}, J=7.6 \mathrm{~Hz})$ & 98.4 \\
\hline $2^{\prime}$ & $3.95(1 \mathrm{H}, \mathrm{dd}, J=8.8,7.6 \mathrm{~Hz})$ & 75.2 & $3.94(1 \mathrm{H}, \mathrm{dd}, J=8.4,7.6 \mathrm{~Hz})$ & 75.2 \\
\hline $3^{\prime}$ & $4.18(1 \mathrm{H}, \mathrm{dd}, J=8.8,8.8 \mathrm{~Hz})$ & 78.9 & $4.14(1 \mathrm{H}, \mathrm{dd}, J=8.8,8.4 \mathrm{~Hz})$ & 78.9 \\
\hline $4^{\prime}$ & $4.09(1 \mathrm{H}, \mathrm{dd}, J=9.6,8.8 \mathrm{~Hz})$ & 71.6 & $4.07(1 \mathrm{H}, \mathrm{dd}, J=9.6,8.8 \mathrm{~Hz})$ & 71.7 \\
\hline $5^{\prime}$ & $3.90(1 \mathrm{H}, \mathrm{ddd}, J=9.6,5.6,2.4 \mathrm{~Hz})$ & 78.2 & $3.90(1 \mathrm{H}, \mathrm{ddd}, J=9.6,5.6,2.4 \mathrm{~Hz})$ & 78.2 \\
\hline $6^{\prime}$ & $\begin{array}{l}4.45(1 \mathrm{H}, \mathrm{dd}, J=11.6,2.4 \mathrm{~Hz}) \\
4.27(1 \mathrm{H}, \mathrm{dd}, J=11.6,5.6 \mathrm{~Hz})\end{array}$ & 63.0 & $\begin{array}{l}4.46(1 \mathrm{H}, \mathrm{dd}, J=11.6,2.4 \mathrm{~Hz}) \\
4.23(1 \mathrm{H}, \mathrm{dd}, J=11.6,5.6 \mathrm{~Hz})\end{array}$ & 62.9 \\
\hline
\end{tabular}

The purity of ginsenoside Rh23 was determined to be more than $99 \%$ by the normalization of the peak areas detected by UPLC analysis. Since UPLC-QTOF/MS has been proven to be a suitable tool for the identification of ginsenoside Rh23, the separation of constituents in HPGL extract was performed by UPLC-QTOF/MS in negative-ion mode. Figure 2 shows a typical total ion chromatogram (TIC) of ginsenoside Rh23 and extract with mass detection.

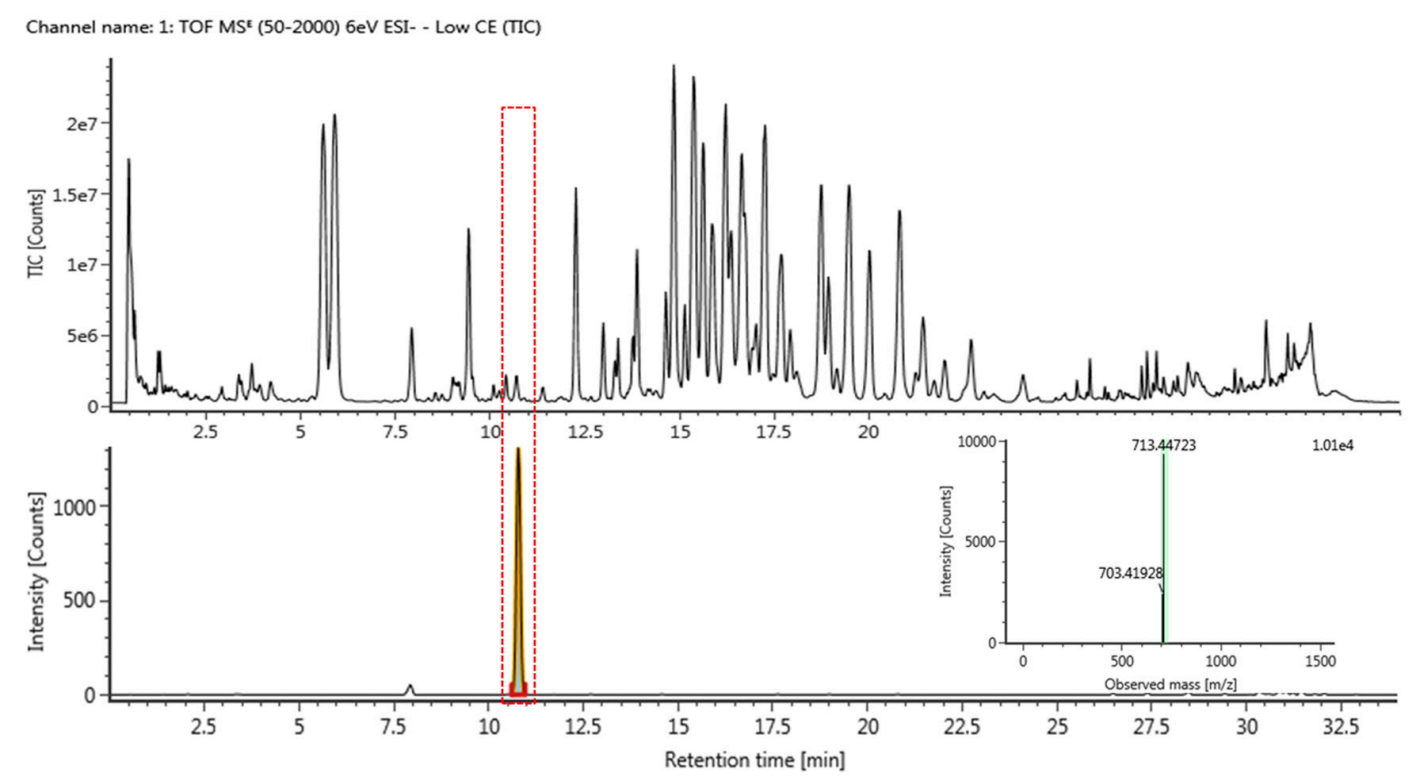

Figure 2. TIC of HPGL extract and ginsenoside Rh23 by UPLC-QTOF/MS in negative-ion mode by selected ion monitoring, and representative QTOF/MS chromatograms 
A linear calibration curve was obtained for ginsenoside Rh23 at different concentration levels. The characteristics of the calibration plots are summarized in Table 2. As seen in the table, ginsenoside Rh23 shows excellent correlation coefficients. Detector counts (relative peak area) were linearly dependent on the sample concentration over the range of $0.02-0.8 \mu \mathrm{g} / \mathrm{mL}$ for ginsenoside Rh23. The LODs of ginsenoside Rh23 was $0.002 \mathrm{ppm}$. The LOQs of ginsenoside Rh23 was determined to be 0.005 ppm by UPLC-QTOF/MS in negative-ion mode. The amount of ginsenoside Rh23 in the HPGL obtained using validation methods (Table 2) was $0.319 \mathrm{mg} / \mathrm{g}$.

Table 2. Linear regression data and contents of the validated method for the ginsenoside Rh23 in HPGL extract ${ }^{\mathrm{a}}$.

\begin{tabular}{|c|c|c|c|c|c|c|c|}
\hline Compounds & $\mathbf{R}_{t}{ }^{b}(\min )$ & $\begin{array}{l}\text { Calibration } \\
\text { Curve }^{\mathrm{c}}\end{array}$ & $\mathbf{R}^{2}$ & $\begin{array}{c}\text { Line Arrange } \\
(\mu \mathrm{g} / \mathrm{mL})\end{array}$ & $\begin{array}{l}\mathrm{LOD}^{\mathrm{d}} \\
(\mathrm{ppm})\end{array}$ & $\begin{array}{l}\mathrm{LOQ}^{\mathrm{e}} \\
(\mathrm{ppm})\end{array}$ & $\begin{array}{c}\text { Amount } \\
(\mathrm{mg} / \mathrm{g})\end{array}$ \\
\hline $\mathrm{Rh} 23$ & 10.79 & $y=351 x+34.9$ & 0.996 & $0.02-0.8$ & 0.002 & 0.005 & 0.319 \\
\hline
\end{tabular}

${ }^{\mathrm{a}}$ Mean values of samples $(n=3) .{ }^{\mathrm{b}} \mathrm{Rt}$, retention time. ${ }^{\mathrm{c}} y$, logarithmic value of peak area; $x$, logarithmic value of amount injected. ${ }^{\mathrm{d}} \mathrm{LOD}$, limit of detection. ${ }^{\mathrm{e}} \mathrm{LOQ}$, limit of quantification.

To determine anti-melanogenic activity, the change in the melanin content in melan-a cells treated with purified and identified compounds was studied. Melan-a cells were treated for $72 \mathrm{~h}$ with compounds 1 and 2 at concentrations ranging from 0 to $80 \mu \mathrm{M}$, and cell viability was assessed via CCK-8 cell viability assay kit. The cell viability of compound $\mathbf{1}$ and $\mathbf{2}$ at $80 \mu \mathrm{M}$ concentration for melan-a cell was over $98.1 \%$ and $97.8 \%$, respectively (data not shown). These results clearly indicated compounds 1 and 2 have a non-cytotoxic nature. The effect of anti-melanogenic activities of compounds are shown in Figure 3. The inhibition of melanin synthesis of compound 1 at 20,40, and $80 \mu \mathrm{M}$ was $8.4 \%, 15.6 \%$ and $37.0 \%$ compared to the control. Compound 2 showed slightly lower inhibitory activity than compound 1 at $7.6 \%, 12.8 \%$ and $17.8 \%$ at 20,40 , and $80 \mu \mathrm{M}$, respectively. Both compounds inhibited melanin synthesis in a dose-dependent manner. Notably, compound 1 showed the highest melanin inhibitory activity, $37.0 \%$ at $80 \mu \mathrm{M}$ concentration. Reportedly, extract of radix ginseng at 0-1000 $\mathrm{gg} / \mathrm{mL}$ did not exhibit any significant inhibition of melanin [19], and cinnamic acid, a whitening agent mainly found in P. ginseng, showed $29 \%$ inhibition of melanin synthesis at $675 \mu \mathrm{M}$ [20]. Compared with the extract of radix ginseng and cinnamic acid, compound 1 showed potent melanin synthesis inhibitory activity, and even showed a 1.2-fold higher inhibitory activity of melanin synthesis at eight-fold lower concentration compared with cumaric acid [17,20].

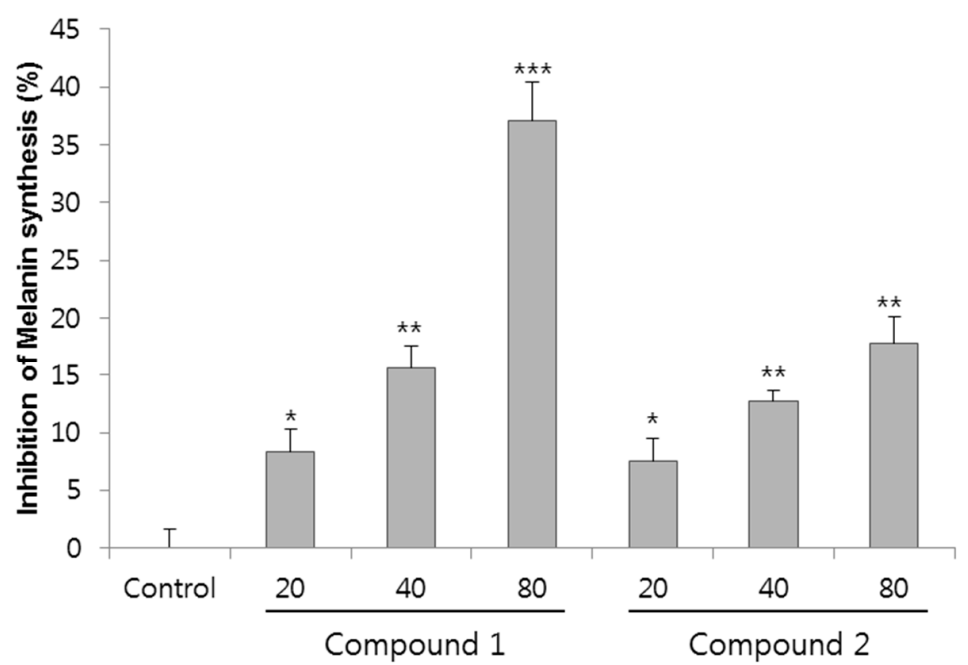

Figure 3. Effects of compounds 1 and 2 on melanogenesis in melan-a cells. The cells were cultured with 0-80 $\mu \mathrm{M}$ of eight compound for four days. Inhibition of melanin synthesis was measured with triplicate experiments. Data are expressed a means \pm SD of triplicate determinations. ${ }^{*} p<0.05,{ }^{* *} p<0.01$, $* * * p 0.001$ versus the control group. 
The zebrafish is a highly advantageous vertebrate model organism because of its similar organ systems and gene sequences to human beings [25]. Furthermore, the use of zebrafish embryos is receiving increasing attention since they are considered a replacement method for animal experiments [26]. Zebrafish have melanin pigments on the surface, allowing simple observation of the pigmentation process without complicated experimental procedures [27]. Thus, we investigated the melanin inhibitory effects of compound $\mathbf{1}$ on the pigmentation of zebrafish. We used PTU ( $N$-phenylthiourea; a sulfur-containing tyrosinase inhibitor) as a positive control (Figure 4B), which is used widely in zebrafish research [28,29]. As shown in Figure 4C,D, 40 and $80 \mu \mathrm{M}$ treatment with compound 1 produced remarkable inhibition of the zebrafish body pigmentation, which remarkably decreased the total melanin content compared with the control vehicle (Figure 4A).

(A)

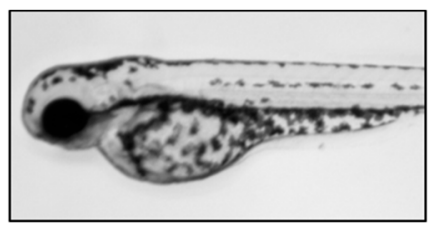

(B)

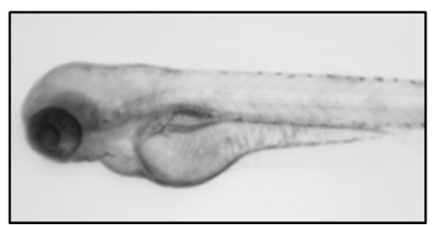

(C)

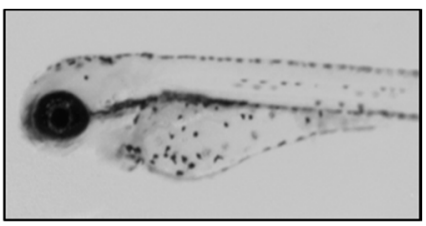

(D)

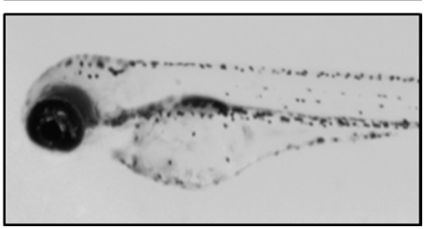

Figure 4. Effects of compound 1 on melanogenesis in zebrafish. Synchronized embryos were treated with melanogenic inhibitors at the indicated concentrations. Compound 1 was dissolved in $0.1 \%$ DMSO and then added to the embryo medium. The effects on pigmentation of zebrafish were observed under the stereomicroscope: (A) (vehicle control) untreated zebrafish embryo; (B) (positive control) $100 \mu \mathrm{M}$ 1-phenyl-2-thiourea (PTU); (C) $40 \mu \mathrm{M}$ compound 1; and (D) $80 \mu \mathrm{M}$ compound 1.

In this study, we isolated novel ginsenoside Rh23 (1) from hydroponic P. ginseng leaves. Thus far, more than 100 ginsenosides have been reported from ginseng species. However, 25-hydroxylated ginsenosides rarely occur in nature, including in ginseng plants. In addition, whitening activity had not been reported. The inhibitory activity of ginsenoside Rh23 showed the $37 \%$ at the $80 \mu \mathrm{M}$ concentration without cell cytotoxicity in melan-a cells, whereas no inhibition of in vitro mushroom tyrosinase activity was observed by ginsenoside Rh23 (data not shown). Recently, the extracts or purified ginsenosides from ginseng roots and leaves have been shown to widely possess anti-oxidant properties [30,31], while water or organic extract of ginseng has exhibited scavenging activities towards $\mathrm{DPPH}$, superoxide anion and hydroxyl radical [32]. Therefore, our novel ginsenoside Rh23 isolated from the leaves of hydroponic $P$. ginseng may have down-regulated tyrosinase by its anti-oxidative property. However, its melanogenesis role has not been clearly investigated yet. Therefore, in further study, it is necessary to determine the precise mechanisms of ginsenoside Rh23 action on the regulation of melanin synthesis.

\section{Experimental}

\subsection{General}

Kieselgel 60 and LiChroprep RP-18 resins were used for column chromatography (Merck, Darmstadt, Germany). Kieselgel $60 \mathrm{~F}_{254}$ (Merck) and RP-18 $\mathrm{F}_{254 \mathrm{~S}}$ (Merck) were used as solid phases for TLC experiment. Detection of spots on the TLC plate was performed by observation under a UV lamp (Spectroline, model ENF-240 C/F, Spectronics Corp., New York, NY, USA) or by spraying $10 \%$ aqueous $\mathrm{H}_{2} \mathrm{SO}_{4}$ on the developed plate followed by heating. Optical rotations were measured using a JASCO P-1010 digital polarimeter (Tokyo, Japan). Melting points were obtained using 
a Fisher-Johns Melting Point Apparatus (Fisher scientific company, Pittsburgh, PA, USA) with a microscope. Ultraviolet spectra were measured on a Shimadzu model UV-1601 spectrophotometer (Shimadzu Corp., Kyoto, Japan). IR spectra were obtained from a Perkin Elmer Spectrum One FT-IR spectrometer (Buckinghamshire, UK). NMR spectra were recorded on a Varian Inova AS 400 spectrometer (400 MHz, Varian, Palo Alto, CA, USA). UPLC-QTOF/MS analysis was performed using a Waters Xevo G2-S series (Waters Corp., Milford, MA, USA) operating in the negative ion mode.

\subsection{Plant Materials}

Hydroponic Panax ginseng was grown in the greenhouse of the Department of Herbal Crop Research located in Eumseong, Chungbuk Province according to the protocol of "ginseng GAP standard cultivation guide" [11,33] developed by the Rural Development Administration, Republic of Korea. One-year-old ginseng seedling roots weighing 0.8 to $1 \mathrm{~g}$ were purchased from Department of Herbal Crop Research, National Institute of Horticultural and Herbal Science (NIHHS), Rural Development Administration (RDA) and stored in a chamber at low temperature $\left(1-2{ }^{\circ} \mathrm{C}\right)$ before use. The ginseng seedling roots were transplanted to nutrient baths and cultured in the hydroponic system. After three months of culture, the hydroponic ginsengs were pulled out for harvesting. The harvested hydroponic ginseng plants were washed clean of dust with water and sorted into leaves and roots, which were then dried for $72 \mathrm{~h}$ in a freeze dryer (FD8512, Ilshin Biobase Co., Yangju, Korea). Voucher specimen (NIHHS14-03) was deposited at the herbarium of the Department of Herbal Crop Research, NIHHS, RDA, Eumseong, Republic of Korea.

\subsection{Extraction and Isolation}

The dried and powdered leaves of hydroponic P. ginseng (HPGL, $6 \mathrm{~kg}$ ) were extracted with $80 \%$ $\mathrm{MeOH}(30 \mathrm{~L} \times 3)$ at room temperature for $24 \mathrm{~h}$. The extracts were filtered through filter paper and evaporated under reduced pressure at $45^{\circ} \mathrm{C}$ to yield $1.4 \mathrm{~kg}$ of extract. The extract was poured into $\mathrm{H}_{2} \mathrm{O}(3 \mathrm{~L})$ and extracted with EtOAc $(3 \mathrm{~L} \times 3)$ and $n$-BuOH $(2.6 \mathrm{~L} \times 3)$, successively. Each layer was concentrated under reduced pressure to obtain EtOAc (75 g), $n$ - $\mathrm{BuOH}(470 \mathrm{~g})$, and $\mathrm{H}_{2} \mathrm{O}(855 \mathrm{~g})$ fractions. The $n$ - $\mathrm{BuOH}$ fraction (HPGLB, $130 \mathrm{~g})$ was applied to the silica gel column $(\phi 13 \times 17 \mathrm{~cm})$ and eluted with $\mathrm{CHCl}_{3}-\mathrm{MeOH}-\mathrm{H}_{2} \mathrm{O}$ (8:3:1, $90 \mathrm{~L} \rightarrow$ 6:4:1, $110 \mathrm{~L}$ ) to yield 20 fractions (HPGLB1 to HPGLB20). Fractions HPGLB3 and HPGLB4 were combined $(18.9 \mathrm{~g}, \mathrm{Ve} / \mathrm{Vt}=0.05-0.12)$, and further fractionated over the silica gel column $\left(\phi 8 \times 15 \mathrm{~cm}, \mathrm{CHCl}_{3}-\mathrm{MeOH}-\mathrm{H}_{2} \mathrm{O}=12: 3: 1,14 \mathrm{~L}\right)$ to yield 14 fractions (HPGLB3-1 to HPGLB3-14). Fractions HPGLB3-4 and HPGLB3-5 were combined (1.27 g, Ve/Vt = 0.09-0.16), and further fractionated over the ODS column $\left(\phi 4 \times 7 \mathrm{~cm}, \mathrm{MeOH}-\mathrm{H}_{2} \mathrm{O}=2: 1,2.6 \mathrm{~L}\right)$ to yield nine fractions (HPGLB3-4-1 to HPGLB3-4-9). Fraction HPGLB3-4-3 (119.4 mg, Ve/Vt $=0.14-0.26)$ was further fractionated over the ODS column $\left(\phi 2.5 \times 7 \mathrm{~cm}, \mathrm{MeOH}-\mathrm{H}_{2} \mathrm{O}=1: 1,1 \mathrm{~L}\right)$ to yield nine fractions (HPGLB3-4-3-1 to HPGLB3-4-3-9) including compound 1 (HPGLB3-4-3-7, $10.5 \mathrm{mg}$, Ve/ Vt = 0.42-0.55, $\mathrm{TLC} \mathrm{R}_{\mathrm{f}}=0.40\left(\mathrm{RP}-18 \mathrm{~F}_{254 \mathrm{~S}}, \mathrm{MeOH}-\mathrm{H}_{2} \mathrm{O}=2: 1\right), \mathrm{R}_{\mathrm{f}}=0.50\left(\right.$ Kieselgel $\left.60 \mathrm{~F}_{254}, \mathrm{CHCl}_{3}-\mathrm{MeOH}-\mathrm{H}_{2} \mathrm{O}=7: 3: 1\right)$ ). Fractions HPGLB5 to HPGLB7 were combined $(24.0 \mathrm{~g}$, Ve/Vt $=0.12-0.22)$, and further fractionated over the silica gel column $\left(\phi 7 \times 12 \mathrm{~cm}, \mathrm{CHCl}_{3}-\mathrm{MeOH}-\mathrm{H}_{2} \mathrm{O}=10: 3: 1,10 \mathrm{~L} \rightarrow 6: 4: 1,9 \mathrm{~L}\right)$ to yield 16 fractions (HPGLB5-1 to HPGLB5-16). Fraction HPGLB5-6 $(323.1 \mathrm{mg}, \mathrm{Ve} / \mathrm{Vt}=0.28-0.31)$ was further fractionated over the ODS column $\left(\phi 3 \times 14 \mathrm{~cm}, \mathrm{MeOH}-\mathrm{H}_{2} \mathrm{O}=3: 2,1.2 \mathrm{~L} \rightarrow 3: 1,1.5 \mathrm{~L}\right)$ to yield ten fractions (HPGLB5-6-1 to HPGLB5-6-10) including compound 2 (HPGLB5-6-5, $10.1 \mathrm{mg}$, Ve/Vt $=0.21-0.23$, TLC $\mathrm{R}_{\mathrm{f}}=0.50\left(\mathrm{RP}-18 \mathrm{~F}_{254 \mathrm{~S}}, \mathrm{MeOH}-\mathrm{H}_{2} \mathrm{O}=2: 1\right), \mathrm{R}_{\mathrm{f}}=0.45\left(\right.$ Kieselgel $\left.60 \mathrm{~F}_{254}, \mathrm{CHCl}_{3}-\mathrm{MeOH}-\mathrm{H}_{2} \mathrm{O}=7: 3: 1\right)$ ).

\subsection{Spectroscopic Data}

Compound 1. White powder, m.p.: $138-140^{\circ} \mathrm{C} ;[\alpha]_{\mathrm{D}}^{25}+17.4^{\circ}(c=0.39, \mathrm{MeOH}) ; \mathrm{IR}\left(\mathrm{CaF}_{2}\right.$ window): 3377, 2932, $1382 \mathrm{~cm}^{-1}$; negative QTOF/MS m/z $713.44723[\mathrm{M}+\mathrm{COOH}]^{-}$(calcd. for $\mathrm{C}_{37} \mathrm{H}_{64} \mathrm{O}_{10}$, 668.4499); ${ }^{1} \mathrm{H}$ - and ${ }^{13} \mathrm{C}-\mathrm{NMR}$ data, see Table 1. 
Compound 2. White powder, m.p.: $133-136^{\circ} \mathrm{C} ;[\alpha]_{\mathrm{D}}^{25}+20.2^{\circ}(c=0.50, \mathrm{MeOH}) ; \mathrm{IR}\left(\mathrm{CaF}_{2}\right.$ window $)$ : 3359, 2929, $1384 \mathrm{~cm}^{-1}$; negative QTOF/MS m/z $699.48311[\mathrm{M}+\mathrm{COOH}]^{-}$(calcd. for $\mathrm{C}_{36} \mathrm{H}_{62} \mathrm{O}_{10}$, 654.4323); ${ }^{1} \mathrm{H}$ - and ${ }^{13} \mathrm{C}-\mathrm{NMR}$ data, see Table 1.

\subsection{Quantitative Analysis of Novel Compound 1 Using UPLC-QTOF/MS}

Standard stock solution of compound 1 was prepared by dissolving $1.00 \mathrm{mg}$ each in $1 \mathrm{~mL}$ methanol to yield a concentration of $1.00 \mathrm{mg} / \mathrm{mL}$ and were kept at $4{ }^{\circ} \mathrm{C}$. The standard stock solution (1) was diluted with methanol to obtain calibration solutions with ranges of $0.02-0.8 \mu \mathrm{g} / \mathrm{mL}$, respectively. One gram of HPGL extract was accurately weighed and dissolved in fixed volumes $(10 \mathrm{~mL})$ of methanol, filtered through a $0.20 \mathrm{~mm}$ filter paper, and refrigerated at $4{ }^{\circ} \mathrm{C}$. UPLC was performed using a Waters ACQUITY H-Class UPLC (Waters Corp., Milford, MA, USA) with an ACQUITY BEH C18 column $(2.1 \times 100 \mathrm{~mm}, 1.7 \mu \mathrm{m})$. The mobile phases consisted of water $(\mathrm{A})$ with $0.1 \%$ formic acid $(v / v)$ and acetonitrile (B) with $0.1 \%$ formic acid $(v / v)$. The elution gradient was as follows: $0-4 \mathrm{~min}$, B 10-30\%; 4-15 min, B 30-60\%; 15-16 $\mathrm{min}, \mathrm{B} 60-100 \%$; $16-19 \mathrm{~min}, \mathrm{~B} 100-10 \%$. The flow rate was $0.45 \mathrm{~mL} / \mathrm{min}$, and the injection volume was $2 \mu \mathrm{L}$ for each run. Next, HR-MS analysis was performed using a Waters Xevo G2-S QTOF MS (Waters Corp., Milford, MA, USA) operating in negative ion mode. The mass spectrometers performed alternating high- and low-energy scans known as MS ${ }^{\mathrm{E}}$ acquisition mode. Accurate mass measurements were obtained by means of an automated calibration delivery system containing Leucine enkephalin, $m / z 554.262$ (ESI neg. mode) as an internal reference. Optimal operating parameters were set as shown in Table 3.

Table 3. Optimal conditions for the Q-TOF/MS analysis of HPGL extract.

\begin{tabular}{cc}
\hline \multicolumn{2}{c}{ Optimal Q-TOF/MS Condition } \\
\hline Ion Source & ESI Negative Mode \\
\hline Source Temp. and Desolvation Temp. & $120{ }^{\circ} \mathrm{C} / 550{ }^{\circ} \mathrm{C}$ \\
Cone Gas Flow and Desolvation Gas Flow & $30 \mathrm{~L} / \mathrm{h} / 800 \mathrm{~L} / \mathrm{h}$ \\
Capillary Volt and Cone Volt & $3 \mathrm{k} / 40 \mathrm{~V}$ \\
Mass Range $(m / z)$ & 50 to 1000 \\
Collision Energy Range & 4 to $45 \mathrm{eV}$ \\
\hline
\end{tabular}

\subsection{Cell Culture}

Melan-a melanocytes are a highly-pigmented, immortalized, normal murine melanocyte cell line derived from C57BL/ 6 mice. The melan-a cells used in this study were obtained from Dr. Dorothy Bennett (St. George's Hospital, London, UK). Cells were cultured at $37^{\circ} \mathrm{C}$ in an atmosphere of $95 \%$ air, $10 \% \mathrm{CO}_{2}$ in RPMI 1640 medium supplemented to a final concentration with $10 \%$ heat-inactivated fetal bovine serum, $1 \%$ penicillin/streptomycin, and $200 \mathrm{nM}$ PMA. Cell viability was determinate by CCK-8 cell counting kit-8 (Dojindo Lab., Kumamoto, Japan).

\subsection{Melanin Assay}

Melan-a cells were treated with compounds for $72 \mathrm{~h}$, and then the cells were dissolved in $1 \mathrm{~N}$ $\mathrm{NaOH}$ at $60{ }^{\circ} \mathrm{C}$ for $30 \mathrm{~min}$. Then, the lysates were measured at $450 \mathrm{~nm}$ using a spectrophotometer. The data were normalized to the protein content of the cell lysates. The cell lysates were subsequently processed for the determination of the protein concentration using a BCA protein assay kit (Thermo Fisher Scientific Inc., Rockford, IL, USA).

\subsection{Origin and Maintenance of Parental Fish}

Adult zebrafishes were obtained from a commercial dealer and 10-15 fishes were kept in a $5 \mathrm{~L}$ acrylic tank with the following conditions: $28.5^{\circ} \mathrm{C}$, with a $14 / 10 \mathrm{~h}$ light/dark cycle. Zebrafishes were fed three times a day, six days per week, with TetraMin flake food supplemented with live brine 
shrimps (Artemia salina). Embryos were obtained from natural spawning that was induced at the morning by turning on the light. Collection of embryos was completed within $30 \mathrm{~min}$. All experimental protocols and procedures were approved and conducted according to the approved guidelines and regulations of the Animal Ethics Committee of Chungnam National University (CNU-00866).

\subsection{Compounds Treatment and Phenotype-Based Evaluation}

Synchronized embryos were collected and arrayed by pipette (7-9 embryos per well in 24-well plates containing $1 \mathrm{~mL}$ of embryo medium). Test compounds were dissolved in $0.1 \% \mathrm{DMSO}$, and then added to the embryo medium from nine to $72 \mathrm{~h}$ post-fertilization (h.p.f) ( $63 \mathrm{~h}$ of exposure). The effects on the pigmentation of zebrafish were observed under the stereomicroscope. Occasional stirring, as well as a replacement of the medium, was performed daily to ensure the even distribution of the compounds. In all experiments, $0.2 \mathrm{mM}$ 1-phenyl-2-thiourea (PTU) was used to generate transparent zebrafish without interfering in the developmental process [33], and was considered as a standard positive control. Phenotype-based evaluations of body pigmentation were dechorionated by forceps, anesthetized in tricaine methanesulfonate solution (Sigma-Aldrich, St. Louis, MO, USA), mounted in $3 \%$ methylcellulose on a $35 \mathrm{~mm}$ dish (SPL Lifesciences, Pocheon, Korea), and photographed under the stereomicroscope MZ16 (Leica Microsystems GmbH, Wetzlar, Germany).

\section{Conclusions}

In this study, ginsenoside Rh23 (1) was isolated from hydrophonic Panax ginseng leaves together with 20-O- $\beta$-D-glucopyranosyl-3 $\beta, 6 \alpha, 12 \beta, 20 \beta, 25$-pentahydroxydammar-23-ene (2). We have been generally successful in our attempt to obtain the hypopigmentary effect of compounds from hydroponic $P$. ginseng. Ginsenoside Rh23 and 20-O- $\beta$-D-glucopyranosyl-3 $\beta, 6 \alpha, 12 \beta, 20 \beta, 25$-pentahydroxydammar23-ene have inhibitory activities on melanin biosynthesis without cytotoxic effects in melan-a cell. Additionally, ginsenoside Rh23 enhanced the depigmentation on the zebrafish as an alternative animal model. The decrease of melanin content and pigmentation on the body may have the potential for whitening activity and non-cytotoxic effect is more favorable point because safety is a primary consideration for whitening agent in cosmetic products. Thus, based on our current results, it is important that novel hydrophonic $P$. ginseng compounds can be used as a potential effective skin-lighting agent. Further studies will elucidate the precise mechanisms of ginsenoside Rh23 action on the regulation of melanin synthesis and the relationship between structural characteristics of ginsenoside $\mathrm{Rh} 23$ and melanogenesis, to ascertain whether it is a potential whitening agent for the cosmetic industry. The advantages of hybrid Q-TOF mass spectrometry include not only quality detection capability and sensitivity, but also accurate measurement, making structural elucidations easier. It can be used for qualitative and quantitative determination of minor or novel compounds, which is helpful in improving the quality control of ginseng spices.

Supplementary Materials: ${ }^{1} \mathrm{H}-\mathrm{NMR}$ and ${ }^{13} \mathrm{C}-\mathrm{NMR}$ spectra of $\mathbf{1}$ are available in the Supplementary Materials.

Acknowledgments: This work was conducted with the support of the "Cooperative Research Program for Agriculture Science and Technology Development" (PJ01136203), Rural Development Administration, Republic of Korea. We thank Cheol-Hee Kim (Chungnam National University) for sharing the zebrafish facility.

Author Contributions: D.Y.L. and N.-I.B. conceived and designed the experiments; H.-G.K. and Y.-G.L. isolated the compounds; D.Y.L. elucidated the structures; I.-B.J. contributed to the plant materials preparation; J.H.K. carried out the biological assay and helped with the preparation of the manuscript; J.W.L. and B.-R.C. performed the NMRs, and UPLC-QTOF/MS of the samples; G.-S.K. assisted the revision of the manuscript; and D.Y.L. wrote the paper and managed the research project. All authors read and approved the final manuscript.

Conflicts of Interest: The authors declare no conflicts of interest. The founding sponsors had no role in the design of the study; collection, analyses, or interpretation of the data; writing of the manuscript; or the decision to publish the results. 


\section{References}

1. Ben, E.W.; Michael, W. Medicinal plants of the world. In Shinilbooks; Timber Press Inc.: Portland, OR, USA, 2007.

2. Park, J.D.; Rhee, D.K.; Lee, Y.H. Biological activities and chemistry of saponins from Panax ginseng C.A. Meyer. Phytochemistry 2005, 4, 159-175. [CrossRef]

3. Kwon, S.J.; Chung, D.K. The immune-enhancing effect of mountain gown ginseng, mountain cultivated ginseng, and Panax ginseng. J. Orient. Neuropsychiatry 2004, 15, 89-101.

4. Gillis, C.N. Panax ginseng pharmacology: A nitric oxide link? Biochem. Pharmacol. 1997, 54, 1-8. [CrossRef]

5. Kang, K.S.; Yamabe, N.; Kim, H.Y.; Yokozawa, T. Effect of sun ginseng methanol extract on lipopolysaccharide-induced liver injury in rats. Phytomedicine 2007, 14, 840-845. [CrossRef] [PubMed]

6. Jiang, S.; Ren, D.; Li, J.; Yuan, G.; Li, H.; Xu, G.; Han, X.; Du, P.; An, L. Effects of compound K on hyperglycemia and insulin resistance in rats with type 2 diabetes mellitus. Fioterapia 2014, 95, 58-64. [CrossRef] [PubMed]

7. Kim, H.S.; Lee, E.H.; Ko, S.R.; Choi, K.J.; Park, J.H.; Im, D.S. Effects of ginsenoside Rg3 and Rh2 on the proliferation of prostate cancer cells. Arch. Pharm. Res. 2004, 27, 429-435. [CrossRef] [PubMed]

8. Nocerino, E.; Amato, M.; Izzo, A.A. The aphrodisiac and adaptogenic properties of ginseng. Fitoterapia 2000, 71, S1-S5. [CrossRef]

9. Keum, Y.S.; Park, K.K.; Lee, J.M.; Chun, K.S.; Park, J.H.; Lee, S.K.; Kwon, H.J.; Surh, Y.J. Antioxidant and anti-tumor promoting activities of the methanol extract of heat-processed ginseng. Cancer Lett. 2000, 150, 41-48. [CrossRef]

10. Kim, G.S.; Lee, S.E.; Noh, H.J.; Kwon, H.; Lee, S.W.; Kim, S.Y.; Kim, Y.B. Effects of natural bioactive products on the growth and ginsenoside contents of Panax ginseng cultured in an aeroponic system. J. Ginseng Res. 2012, 36, 430-441. [CrossRef] [PubMed]

11. Choi, S.Y.; Cho, C.W.; Lee, Y.M.; Kim, S.S.; Lee, S.H.; Kim, K.T. Comparison of ginsenoside and phenolic ingredient contents in hydroponically-cultivated ginseng leaves, fruits, and roots. J. Ginseng Res. 2012, 36, 425-429. [CrossRef] [PubMed]

12. Matsuda, H.; Nakamura, S.; Kubo, M. Studies of cuticle drugs from natural sources. II. Inhibitory effects of Prunus plants on melanin biosynthesis. Biol. Pharm. Bull. 1994, 17, 1417-1420. [CrossRef] [PubMed]

13. Duncan, C.L.; Foster, E.M. Effect of sodium nitrite, sodium chloride, and sodium nitrate on germination and outgrowth of anaerobic spores. Appl. Microbiol. 1968, 16, 406-411. [PubMed]

14. Shimizu, K.; Yasutake, S.; Kondo, R. A new stilbene with tyrosinase inhibitory activity from Chlorophora excels. Chem. Pharm. Bull. 2003, 51, 318-319. [CrossRef] [PubMed]

15. Park, S.H.; Kim, D.S.; Kim, W.G.; Ryoo, I.J.; Lee, D.H.; Huh, C.H.; Youn, S.W.; Yoo, I.D.; Park, K.C. Terrin: A new melanogenesis inhibitor and its mechanism. Cell. Mol. Life 2004, 61, 2878-2885. [CrossRef] [PubMed]

16. Kong, Y.H.; Jo, Y.O.; Cho, C.W.; Son, D.W.; Park, S.J.; Rho, J.H.; Choi, S.Y. Inhibitory effects of cinnamic acid on melanin biosynthesis in skin. Biol. Pharm. Bull. 2008, 31, 946-948. [CrossRef] [PubMed]

17. Hwang, E.Y.; Choi, S.Y. Quantitative analysis of phenolic compounds in different parts of Panax ginseng C.A. Meyer and its inhibitory effect on melanin biosynthesis. Korean J. Med. Crop Sci. 2006, 14, 148-152.

18. Im, S.J.; Kim, K.N.; Yun, Y.G.; Lee, J.C.; Mun, Y.J.; Kim, J.H.; Woo, W.H. Effect of radix ginseng and radix trichosanthis on the melanogenesis. Biol. Pharm. Bull. 2003, 26, 849-853. [CrossRef] [PubMed]

19. Hwang, E.Y.; Kong, Y.H.; Lee, Y.C.; Kim, Y.C.; Yoo, K.M.; Jo, Y.O. Comparison of phenolic compounds contents between white and red ginseng and their inhibitory effect on melanin biosynthesis. J. Ginseng Res. 2006, 30, 82-87.

20. Zhang, Y.C.; Pi, Z.F.; Liu, C.M.; Song, F.R.; Liu, Z.Q.; Liu, S.Y. Analysis of low-polar ginsenosides in steamed Panax ginseng at high-temperature by HPLC-ESI-MS/MS. Chem. Res. Chin. Univ. 2012, 28, 31-36.

21. Xie, Y.Y.; Luo, D.; Cheng, Y.J.; Ma, J.F.; Wang, Y.M.; Liang, Q.L.; Luo, G.A. Steaming-induced chemical transformations and holistic quality assessment of red ginseng derived from Panax ginseng by means of HPLC-ESI-MS/MS ${ }^{n}$ based multicomponent quantification fingerprint. J. Agric. Food Chem. 2012, 60, 8213-8224. [CrossRef] [PubMed]

22. Liu, G.Y.; Li, X.W.; Wang, N.B.; Zhou, H.Y.; Wei, W.; Gui, M.Y.; Yang, B.; Jin, Y.R. Three new dammarane-type triterpene saponins from the leaves of Panax ginseng C.A. Meyer. J. Asian Nat. Prod. Res. 2010, 12, 865-873. [CrossRef] [PubMed] 
23. Xing, Q.; Liang, T.; Shen, G.; Wang, X.; Jin, Y.; Liang, X. Comprehensive HILIC x RPLC with mass spectrometry detection for the analysis of saponins in Panax notoginseng. Analyst 2012, 137, 2239-2249. [CrossRef] [PubMed]

24. Love, D.R.; Pichler, F.B.; Dodd, A.; Copp, B.R.; Greenwood, D.R. Technology for high-throughput screen: The present and future using zebrafish. Curr. Opin. Biotechnol. 2004, 15, 564-571. [CrossRef] [PubMed]

25. Uwe, S.; Stefan, S.; Pobert, G.; Petra, G.; Henner, H.; Sepand, R.; Axel, S.; Ingrid, S.; Carsten, W.; Hilda, W.; et al. Zebrafish embryos as an alternative to animal experiments-A commentary on the definition of the onset of protected life stage in animal welfare regulations. Reprod. Toxicol. 2012, 33, 128-132.

26. Chio, T.Y.; Kim, J.H.; Ko, D.H.; Kim, C.H.; Hwang, J.S.; Ahn, S.; Kim, S.Y.; Kim, C.D.; Lee, J.H.; Yoo, T.J. Zebrafish ax a new model for phenotype-based screening of melanogenic regulatory compounds. Pigment Cell Res. 2007, 20, 120-127. [CrossRef] [PubMed]

27. Elsalini, O.A.; Rohr, K.B. Phenylthiourea disrupts thyroid function in developing zebrafish. Dev. Genes Evol. 2003, 212, 593-598. [PubMed]

28. Lee, D.Y.; Cha, B.J.; Lee, Y.S.; Kim, G.S.; Noh, H.J.; Kim, S.Y.; Kang, H.C.; Kim, J.H.; Baek, N.I. The potential of minor ginsenosides isolated from the leaves of Panax ginseng as inhibitors of melanogenesis. Int. J. Mol. Sci. 2015, 16, 1677-1690. [CrossRef] [PubMed]

29. Li, J.; Huang, M.; Teoh, H.; Man, R.Y. Panax quinquefolium saponins protects low density lipoproteins from oxidation. Life Sci. 1999, 64, 53-62. [CrossRef]

30. Li, T.S.C.; Mazza, G.; Cottrell, A.C.; Gao, L. Ginsenosides in roots and leaves of American ginseng. J. Agric. Food Chem. 1996, 44, 717-720. [CrossRef]

31. Jung, C.H.; Seog, H.M.; Choi, I.W.; Park, M.W.; Cho, H.Y. Antioxidant properties of various solvent extracts from wild ginseng leaves. LWT 2006, 39, 266-274. [CrossRef]

32. National Institute of Crop Science. Ginseng GAP Standard Cultivation Guideline; National Institute of Crop Science, Rural Development Administration: Suwon, Korea, 2009.

33. Karlsson, J.; Von Hofsten, J.; Olsson, P.E. Genearting transparent zebrafish: A refined method to improve detection of gene expression during embryonic development. Mar. Biotechnol. 2001, 3, 522-527. [CrossRef] [PubMed]

Sample Availability: Samples of the compounds $\mathbf{1}$ and $\mathbf{2}$ are available from the authors.

(C) 2018 by the authors. Licensee MDPI, Basel, Switzerland. This article is an open access article distributed under the terms and conditions of the Creative Commons Attribution (CC BY) license (http:/ / creativecommons.org/licenses/by/4.0/). 